\title{
Strong innate immune response and cell death in chicken splenocytes infected with genotype VIld Newcastle disease virus
}

\author{
Zenglei Hu${ }^{1}$, Jiao Hu${ }^{1}$, Shunlin $\mathrm{Hu}^{1}$, Xiaowen Liu', Xiaoquan Wang ${ }^{1}$, Jie Zhu ${ }^{1}$ and Xiufan $\mathrm{Liu}^{1,2^{*}}$
}

\begin{abstract}
Background: Genotype VIId Newcastle disease virus (NDV) isolates induce more severe damage to lymphoid tissues, especially to the spleen, when compared to virulent viruses of other genotypes. However, the biological basis of the unusual pathological changes remains largely unknown.

Methods: Virus replication, cytokine gene expression profile and cell death response in chicken splenocytes infected with two genotype VIId NDV strains (JS5/05 and JS3/05), genotype IX NDV strain F48E8 and genotype IV NDV strain Herts/33 were evaluated. Statistical significance of differences between experimental groups was determined using the Independent-Samples $T$ test.

Results: JS5/05 and JS3/05 caused hyperinduction of type I interferons (IFNs) (IFN- $a$ and - $\beta$ ) during detection period compared to F48E8 and Herts/33. JS5/05 increased expression level of IFN- $\gamma$ gene at $6 \mathrm{~h}$ post-inoculation (pi) and JS3/05 initiated sustained activation of IFN- $\gamma$ within $24 \mathrm{~h}$ pi, whereas transcriptional levels of IFN- $\gamma$ remained unchanged at any of the time points during infection of F48E8 and Herts/33. In addition, compared to F48E8 and Herts/33, JS3/05 and JS5/05 significantly increased the amount of free nucleosomal DNA in splenocytes at 6 and $24 \mathrm{~h}$ pi respectively. Annexin- $\mathrm{V}$ and Proidium iodid (PI) double staining of infected cells showed that cell death induced by JS3/05 and JS5/05 was characterized by marked necrosis compared to F48E8 and Herts/33 at $24 \mathrm{~h}$ pi. These results indicate that genotype VIId NDV strains JS3/05 and JS5/05 elicited stronger innate immune and cell death responses in chicken splenocytes than F48E8 and Herts/33. JS5/05 replicated at a significantly higher efficiency in splenocytes than F48E8 and Herts/33. Early excessive cell death induced by JS3/05 infection partially impaired virus replication.
\end{abstract}

Conclusions: Viral dysregulaiton of host response may be relevant to the severe pathological manifestation in the spleen following genotype VIld NDV infection.

Keywords: Innate immune response, Cell death, Splenic necrosis, Genotype VIld Newcastle disease virus

\section{Background}

Genotype VIId Newcastle disease virus (NDV) is dominant in Asia [1-3]. Many pathological studies have revealed that genotype VIId NDV isolates induce the most severe necrosis in lymphoid tissues, especially in the spleen, when compared with virulent isolates of

\footnotetext{
* Correspondence: xfliu@yzu.edu.cn

"Animal Infectious Disease Laboratory, School of Veterinary Medicine, Yangzhou University, 12 East Wenhui Road, Yangzhou Jiangsu Province 225009, China
${ }^{2}$ Ministry of Education Key Lab for Avian Preventive Medicine, School of 225009, China
${ }^{2}$ Ministry of Education Key Lab for Avian Preventive Medicine, School of Veterinary Medicine, Yangzhou University, 12 East Wenhui Road, Yangzhou Jiangsu Province 225009, China
}

(c) 2012 Hu et al.; licensee BioMed Central Ltd. This is an Open Access article distributed under the terms of the Creative Commons Attribution License (http://creativecommons.org/licenses/by/2.0), which permits unrestricted use, distribution, and reproduction in any medium, provided the original work is properly cited. usual pathological manifestation remains unclear.

Although many viral determinants for pathogenicity of NDV have been identified [7-9], few mechanistic data regarding host response to NDV infection are available. Some recent studies have demonstrated that viral modulation of host innate immune response is associated with viral pathogenesis and pathological outcomes $[4,10]$. Similarly, numerous studies in animal and cell models have shown that robust host immune response contributes to the pathogenesis of highly pathogenic avian H5N1 influenza virus [11,12]. 
In addition, apoptosis is associated with the pathogenesis of NDV. Chickens experimentally infected with virulent NDV isolates exhibited prominent apoptosis in lymphoid tissues [13-15]. Moreover, Harrison et al. have shown that the degree of apoptosis in lymphoid tissues is correlated with the severity of disease caused by NDV strains of varying virulence [15].

Based on these findings, we hypothesize that host innate immune response and apoptosis are associated with the severe destruction of lymphoid tissues following genotype VIId NDV infection.

Considering that results in primary cultured cells can be closely correlated with pathogenesis in vivo, we used chicken splenocytes as an in vitro model to compare apoptosis and cytokine response following infection with two genotype VIId NDV strains JS5/05 and JS3/05, a genotype IX NDV strain F48E8 and a genotype IV NDV strain Herts/33.

\section{Results}

\section{Virus replication in splenocytes}

To evaluate difference in replication of NDV strains from different genotypes in chicken splenocytes, we determined virus amounts in culture supernatants and transcriptional levels of viral matrix (M) gene. Titration test showed that culture supernatants of JS5/05-inoculated splenocytes had the largest amount of virus at $6 \mathrm{~h}$ postinoculation (pi) than those of cells inoculated with other tested viruses (Figure 1A). In addition, JS5/05 maintained this high replication efficiency during detection period. At 12 and $24 \mathrm{~h}$ pi, F48E8 also showed high replication efficiency in splenocytes, which is consistent with its high virus titer in chicken embryo fibroblasts (CEF) (Table 1). Moreover, JS3/05 replicated with relative low efficiency when compared to JS5/05 and F48E8. Splenocytes inoculated with Herts/33 released the lowest amount of virus into culture supernatants among these four NDV strains. Data of quantitative real-time polymerase chain reaction (qRT-PCR) agreed with the results of titration assay (Figure 1B). M gene transcription levels of JS5/05 strain were significantly higher than those of F48E8 and Herts/33 strain at any of the time points. However, JS3/05 showed relative low $\mathrm{M}$ gene expression levels than JS5/05 and F48E8, which may be attributed to the early cell death induced by JS3/05 infection (Figure 2). These results suggest that high replication efficiency of genotype VIId NDV in splenocytes was isolate-specific and NDV replication may be partially associated with virus-induced cell death.

\section{Apoptosis assay}

We next quantitatively determined cytoplasmic histoneassociated-DNA-fragments using enzyme linked immunosorbent assay (ELISA) to evaluate virus-induced apoptosis. We only focused on the difference in apoptosis between genotype VIId NDV strains and viruses of other genotypes. As shown in Figure 2, at $6 \mathrm{~h}$ pi, the absorbance value of splenocytes inoculated with JS3/05 was significantly higher than that of cells inoculated with F48E8 and Herts/33. At $12 \mathrm{~h} \mathrm{pi,} \mathrm{the} \mathrm{absorbance} \mathrm{values}$ of splenocytes infected with all viruses were comparable. At $24 \mathrm{~h}$ pi, JS5/05-inocualted cells produced significantly higher absorbance values than those of F48E8- and Herts-inoculated cells. These findings demonstrated that splenocytes infected with genotype VIId NDVs (JS5/05 and JS3/05) were richer in free nucleosomal DNA than those infected with F48E8 and Herts/33, indicating that JS3/05 and JS5/05 induced stronger apoptosis in splenocytes when compared to F48E8 and Herts/33.

\section{Cytokine gene expression profile}

Interferons (IFNs) are important members of host innate arm of immunity to prevent virus infection. However, overproduction of IFNs is also related to cytokine storm
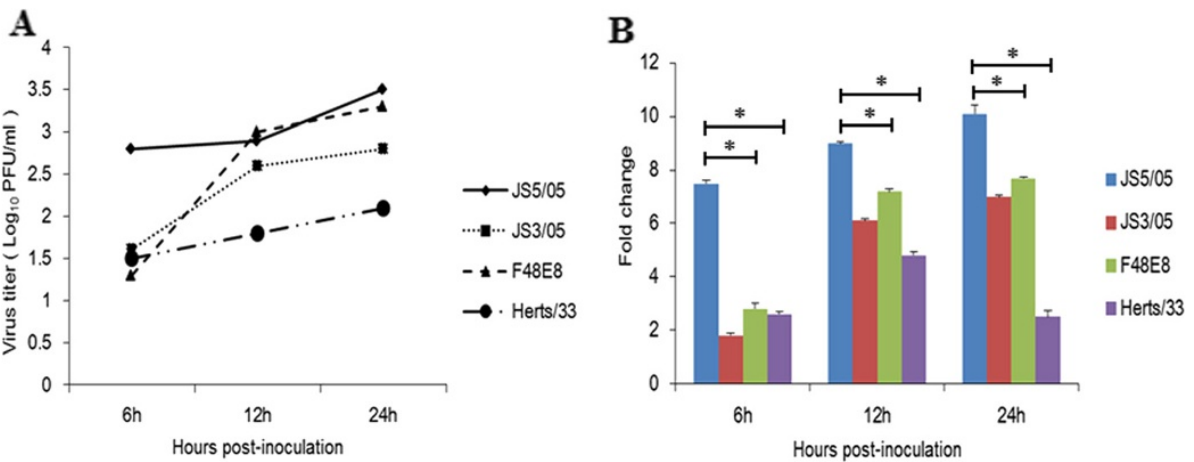

Figure 1 Characterization of virus replication in splenocytes. (A) Virus titration of culture supernatants from virus-infected splenocytes using plaque formation test in CEF. (B) Analysis of viral M gene transcription profiles using qRT-PCR. The transcription levels of viral $M$ gene were normalized to those of $\beta$-actin gene in the corresponding sample. Asterisk $\left(^{*}\right)$ indicates significant difference at $p<0.05(n=3)$ between experimental groups. 
Table 1 Background information of NDV strains used in this study

\begin{tabular}{llllll}
\hline Virus & Host & $\begin{array}{l}\text { Year of } \\
\text { isolation }\end{array}$ & Genotype & $\begin{array}{l}\text { Accession } \\
\text { number }\end{array}$ & $\begin{array}{l}\text { Titer } \\
\left.\text { (TCID }_{\mathbf{5 0}} / \mathbf{m l}_{\mathbf{m}}\right)\end{array}$ \\
\hline JS5/05 & Goose & 2005 & VIld & JN631747 & $10^{9.2}$ \\
JS3/05 & Fowl & 2005 & VIId & JN618349 & $10^{9.2}$ \\
F48E8 & Fowl & 1946 & IX & AY260113 & $10^{10.3}$ \\
Herts/33 & Fowl & 1933 & IV & AY741404 & $10^{8.6}$ \\
\hline
\end{tabular}

that contributes to viral immunopathogenesis. We used qRT-PCR to characterize expression profiles of IFN genes, including IFN $-\alpha$, IFN- $\beta$ and IFN $-\gamma$, to provide insights into the role of innate immune response in pathogenesis of NDV. The results showed that JS3/05 and JS5/05 slightly upregulated expression level of IFN$\alpha$ at 6 and $12 \mathrm{~h}$ pi and these two viruses increased expression values of IFN- $\alpha$ at $24 \mathrm{~h}$ pi (4-fold for JS5/05 and 2-fold for JS3/05) (Figure 3A). However, in F48E8or Herts/33-infected cells, the transcription levels of IFN- $\alpha$ did not appear to change at any of the time points (Figure 3A). Transcription levels of IFN- $\beta$ did not show notable changes at $6 \mathrm{~h}$ pi in cells infected with four tested NDVs. At $12 \mathrm{~h} \mathrm{pi}$, only JS3/05-inoculated cells showed a 2.3 -fold increase of IFN- $\beta$ expression. At $24 \mathrm{~h}$ pi, a 2.8 -fold increase of IFN- $\beta$ expression was detected in splenocytes infected with JS5/05 and 2.2-fold increase for JS3/05. In contrast, IFN- $\beta$ remained unchanged during detection period in F48E8- and Herts/ 33-inoculated cells (Figure 3B). IFN- $\gamma$ RNA amounts were increased by two genotype VIId NDV strains (3.3fold for JS5/05 and 2.5-fold for JS3/05) at $6 \mathrm{~h}$ pi. IFN- $\gamma$ expression levels in JS5/05-inocualted cells decreased at a stepwise pattern at 12 and $24 \mathrm{~h}$ pi. JS3/05 increased expression level of IFN- $\gamma$ gene up to 12 -fold at $12 \mathrm{~h}$ pi and high value (5-fold increase) was also observed at

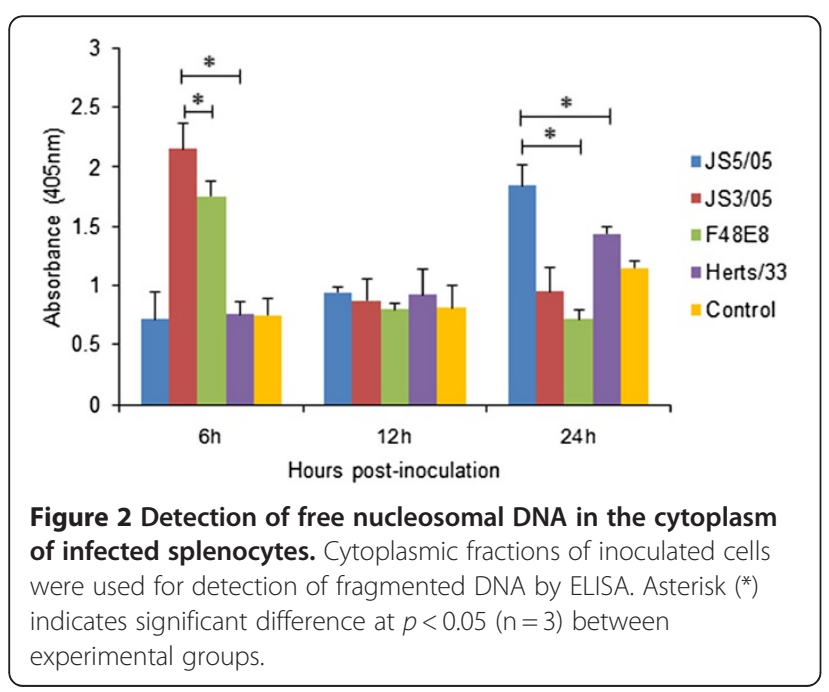

$24 \mathrm{~h}$ pi. However, no marked change in IFN- $\gamma$ expression was found for F48E8 and Herts/33 (Figure 3C). These results suggest that JS5/05 and JS3/05 triggered a more potent innate immune response compared to F48E8 and Herts/33.

\section{Annexin-V and PI double staining}

Virus-induced cytopathic effect (CPE) is related to virus replication efficiency in host cells and virus pathogenicity. Apoptosis is a critical mechanism of NDV-induced CPE. We then used Annexin-V and PI double staining that can differentiate early apoptotic cells and necrotic cells to evaluate morphological changes caused by NDV isolates of different genotypes. At $24 \mathrm{~h}$ pi, splenocyets infected with JS3/05 were characterized with the presence of large amount of cellular DNA released from lysed necrotic cells. Many apoptotic and necrotic cells coexisted in splenocytes infected with JS5/05, and these necrotic cells did not completely lose membrane integrity (Figure 4). This finding is consistent with the high level of free nucleosomal DNA detected using ELISA in JS5/05-inoculated cells at $24 \mathrm{~h}$ pi (Figure 2). In contrast, there were fewer apoptotic and necrotic cells in splenocytes infected with F48E8 and Herts/33 (Figure 4). These results showed that in addition to apoptosis, genotype VIId NDV isolates also induced marked cellular necrosis compared to F48E8 and Herts/33, which may have effect on virus replication and viral pathogenicity.

\section{Discussion}

The biological basis of severe tissue damage in the lymphoid system induced by genotype VIId NDV strains is unknown. We hypothesized that dysregulation of host response may play an important role. In this study, our findings demonstrated that two isolates (JS5/05 and JS3/ 05) of genotype VIId NDV elicited robust innate immune response that was evidenced by upregualtion of IFNs expression compared to genotype IX NDV F48E8 and genotype IV NDV Herts/33. In addition, JS5/05 and JS3/05 also induced enhanced apoptosis and necrosis compared to F48E8 and Herts/33. Virus replication was observed with partial association with virus-induced cell death. Therefore, our in vitro results indicate that dysregulation of host response may contribute to the 


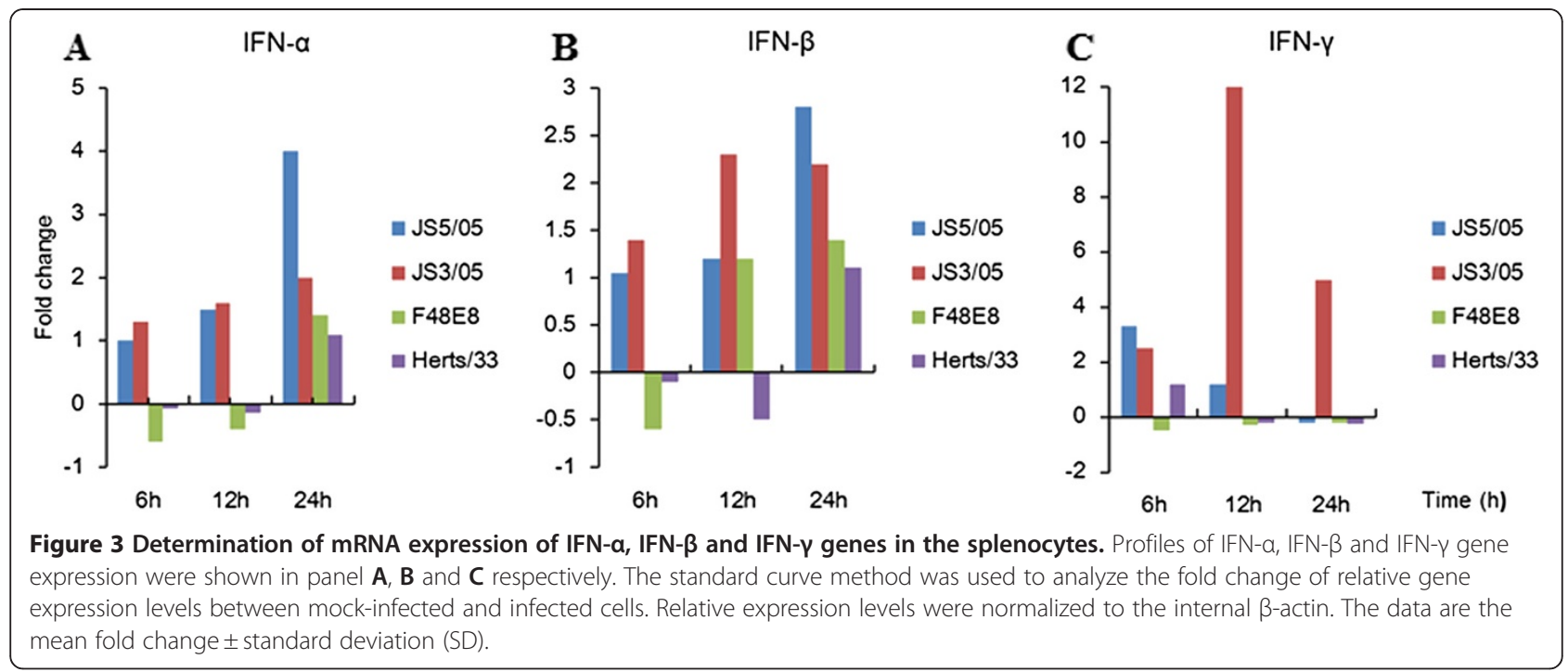

severe spleen pathology caused by genotype VIId NDV infection.

Host cells mount the cytokine response to prevent infection upon virus invasion. However, overproduction of cytokines may form a cytokine storm to amplify detrimental effect of inflammation on the host [16]. In this study, quantitative analysis of transcription levels of IFN genes showed that JS5/05 and JS3/05 increased expression levels of IFN- $\alpha$, IFN- $\beta$ and IFN- $\gamma$ compared to
F48E8 and Herts/33, indicating that genotype VIId NDV strains induce a more potent IFN response (Figure 3). Therefore, strong activation of IFN response may intensify inflammation that causes damages in tissue structures. It is notable that hyperinduction of IFN- $\gamma$, a key pro-inflammatory cytokine, may increase synthesis of nitric oxide that has toxic effect on host. IFNs are a family of cytokines that play a central role in innate immunity to viruses. The correlation of JS5/05-induced high levels

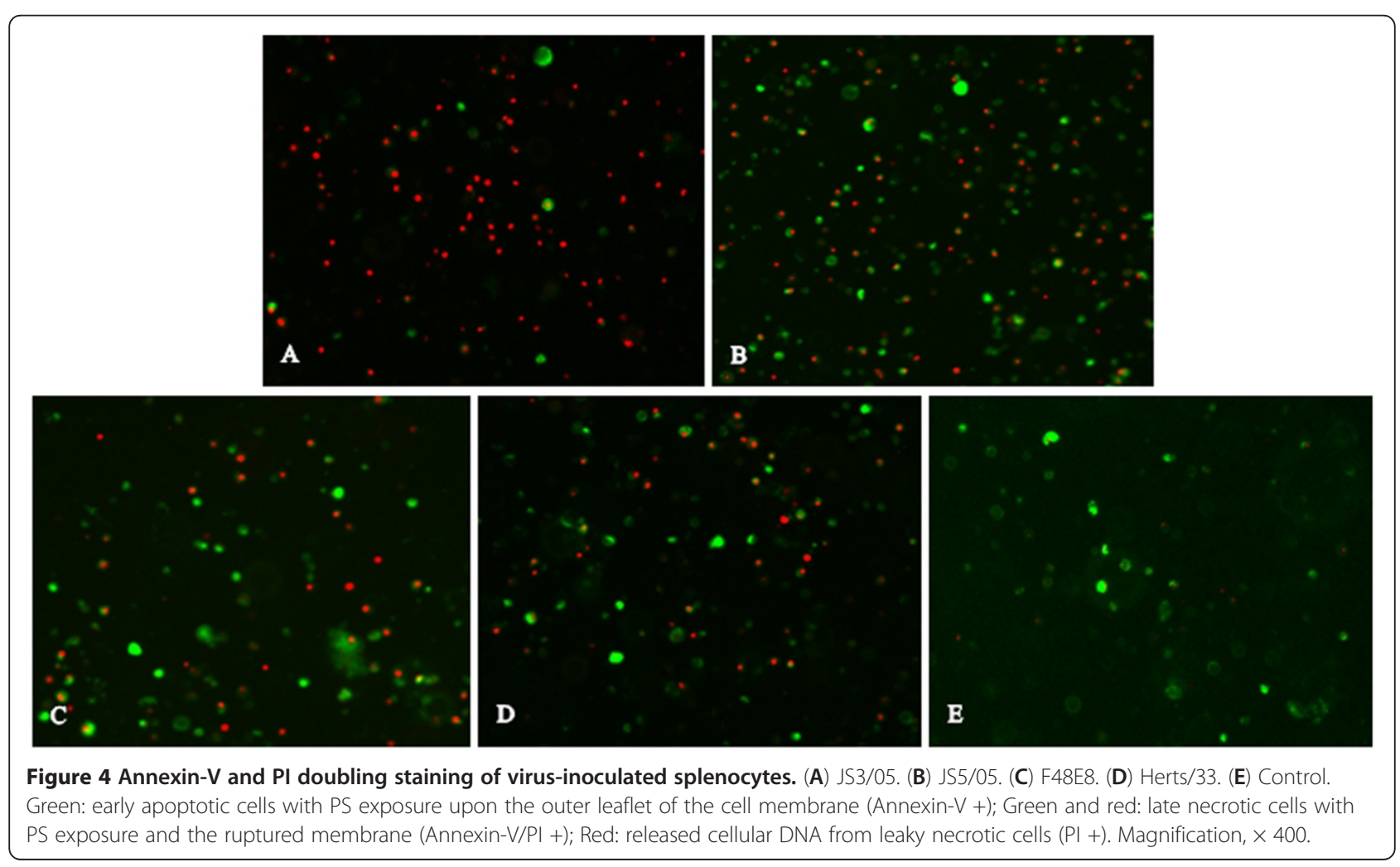


of IFNs and high virus load may result from the faster virus replication to overcome anti-viral effect of IFNs. Additionally, NDV V protein serves as an antagonist of alpha IFN and contributes to viral virulence [17]. Our data showed that at least at mRNA level, a block of IFN function did not occur during infection with JS5/05 and JS3/05. Perhaps these two isolates can activate many genes that involved in IFN pathway to overwhelm the suppression effect of $\mathrm{V}$ protein.

In addition to the role in inflammation and anti-virus activity, IFNs also act as key mediators of apoptosis [18]. Many factors involved in IFN signaling pathway, such as IFN regulatory factors (IRFs), protein kinase $R$ (PKR) and 2',5-oligoadenylate/RNaseL system, contribute to apoptosis through different mechanisms. IFNs can also induce the activation of TNF-related apoptosis-inducing ligand (TRAIL) that initiates the death receptormediated cell death [18].

Here we showed that JS5/05 and JS3/05 induced stronger apoptosis than F48E8 and Herts/33, reflected by the significantly larger amount of free nucleosomal DNA in JS5/05- and JS3/05-inucolated cells (Figure 2). In addition, splenocytes inoculated with JS3/05 and JS5/05 also underwent marked necrosis (Figure 4). One possible consequence is that stronger cell death in splenocytes infected with JS5/05 and JS3/05 may accelerate disease severity. It has been shown that apoptosis in lymphoid tissues in NDV-infected birds was followed by extensive lymphocellular necrosis [13,14]. Harrison et al. have demonstrated that the apoptotic rate is proportional to the disease severity produced by NDV strains of varying virulence [15]. Accumulating evidence has shown that the pathogenicity of avian influenza virus H5N1 is closely associated with virus-induced apoptosis [19-21]. Of particular interest, as an alternate form of programmed cell death, necrosis may have different effects on disease severity from that of apoptosis. Necrotic cells will release the cytoplasmic contents into the extracellular fluid to stimulate inflammatory response [22].

Based on our findings, we could speculate that cytokine response and cell death may act in concert to exacerbate the disease severity caused by genotype VIId NDV. Our results also indicate that viral dysregulation of host response by genotype VIId NDV strains may be a genotype-specific phenotype.

It is commonly assumed that efficiency of virus replication is an important determinant for the severity of disease. NDV can propagate in chicken lymphocytes and cause lymphocyte depletion, which lead to severe consequences for bird immune system [13,14,23,24]. Replication efficiency of JS5/05 in splenocytes was significantly higher than that of F48E8 and Herts/33, whereas replication efficiency of JS3/05 was partially inhibited by the early strong apoptosis (Figure 1). Thus, high replication capacity of genotype VIId NDV in splenocytes may be virus-dependent. Our results also suggest that in vitro replication of NDV may be determined by various factors, including cell type, viral genes and virus-induced $\mathrm{CPE}$. Moreover, there may be an active interplay between virus replication and virus-induced cell death. At the early stage of infection, JS5/05 induced low-level apoptosis that allowed high virus replication, whereas excessive apoptosis induced by JS3/05 inhibited virus replication. Reversely, at the late phase of infection, JS5/05-induced cell death may promote virus replication, which may result from the failure of dead lymphocytes to clear virus and active virus release from leaky necrotic cells.

Our data are consistent with some previous findings. Rue et al. have demonstrated that virulent NDV elicits a robust host response in the spleen represented by hyperinduction of many cytokines, suggesting a correlation between pathogenicity and host innate immune response [10]. Ecco et al. have shown that the genotype VIId NDV strain ZJ1 is a stronger inducer of cytokine response than other virulent strains and the high-cytokine phenotype is consistent with viral pathogenicity and disease outcome [4].

Although there are many studies performed to elucidate virus pathogenicity and host response to NDV strains of varying virulence, evidence focusing on differences in virus-host interplay of different virulent isolates is limited. Our study presents in vitro evidence that differential viral modulation of host response corresponds with the contrasting histopathology phenotypes. Based on these results, we are performing animal experiments to provide supporting in vivo results to confirm this correlation.

\section{Conclusions}

In summary, genotype VIId NDV isolates (JS5/05 and JS3/05) induced stronger innate immune and cell death responses than genotype IX NDV strain F48E8 and genotype IV NDV strain Herts/33 in chicken splenocytes. This in vitro evidence indicates that dysregulation of host response may contribute to severe tissue damage in the lymphoid system caused by genotype VIId NDV. This study also highlights that besides standard pathogenicity indices, evaluation of viral-host interaction is required for full characterization of NDV isolates.

\section{Methods}

\section{Ethics statement}

Experimental research on animals was approved by the Jiangsu Administrative Committee for Laboratory Animals (Permission number: SYXK-SU-2007-0005), and complied with the guidelines of Jiangsu laboratory 
animal welfare and ethical of Jiangsu Administrative Committee of Laboratory Animals.

\section{Viruses and cells}

Details for viruses used in this study were listed in Table 1. Viruses were plaque-purified three times in CEF. These viruses were propagated in the allantoic cavities of 9-day-old specific-pathogen-free (SPF) embryonated chicken eggs. Virus titers were determined as 50\% tissue culture infective dose $\left(\mathrm{TCID}_{50}\right)$ in $\mathrm{CEF}$.

Chicken splenocytes were isolated as previously reported [10]. Briefly, single-cell suspensions were prepared by cutting the spleens into small pieces, gently dissociating the spleen pieces on a sterile copper wire mesh, and then purified by gradient centrifugation $(500 \times \mathrm{g}, 30 \mathrm{~min})$ using Histopaque 1077 (Sigma, St. Louis, USA). After washing with phosphate-buffered saline (PBS) for three times, splenocytes were resuspended in RPMI 1640 medium (Invitrogen, CA, USA).

\section{In vitro infection}

Viable cells were counted using trypan blue exclusion prior to infection. Total amount of splenocytes needed were inoculated with NDV strains at a multiplicity of infection (MOI) of 1 . Infected cells were seeded at $1 \times 10^{6}$ cells/well in 24-well-plates. Samples were collected at 6, 12 and $24 \mathrm{~h}$ pi.

\section{Virus replication assays}

Viral replication was analyzed through two different ways. Virus contents in culture supernatants were quantified using standard plaque assay in CEF. In addition, transcription levels of viral $\mathrm{M}$ gene were determined using qRT-PCR. Primers for $M$ genes (Table 2) were designed based on the conserved sequences that were identified using the Megalign program (DNASTAR, Madison, WI, USA).

\section{Cytokine gene expression}

To determine host innate immune response to virus infection, the mRNA expression levels of IFN- $\alpha$, IFN- $\beta$ and IFN- $\gamma$ were analyzed using a two-step qRT-PCR. Primers for these cytokine genes were listed in Table 2.
Total RNA was isolated from splenocytes using the TRIzol reagent (Invitrogen, CA, USA). 100 nanogram (ng) of total RNA per sample was treated with $1 \mathrm{U}$ DNase I (Fermentas, Maryland, USA) and used for reverse transcription reaction using $40 \mathrm{U}$ M-MuLV reverse transcriptase (Fermentas, Maryland, USA) and $20 \mu \mathrm{M}$ random primers in the presence of RNase inhibitor (Takara, Shiga, Japan) at $42^{\circ} \mathrm{C}$ for $90 \mathrm{~min}$. cDNA and $200 \mathrm{nM}$ (final concentration) each primer were mixed with $10 \mu \mathrm{l}$ of $2 \times$ SYBR Green PCR Master Mix (Takara). Reactions were performed in triplicate using the $\mathrm{ABI}$ Prism 7300 system with the following cycle profile: 1 cycle at $50^{\circ} \mathrm{C}$ for $2 \mathrm{~min}$ and 1 cycle at $95^{\circ} \mathrm{C}$ for $5 \mathrm{~s}$ followed by 40 cycles at $95^{\circ} \mathrm{C}$ for $5 \mathrm{~s}$ and $60^{\circ} \mathrm{C}$ for $31 \mathrm{~s}$. 1 cycle for dissociation curve for all reactions was added. Relative expression levels were normalized using an internal $\beta$-actin control. The standard curve method was used to analyze the fold change of relative gene expression levels.

\section{Apoptosis assay}

To measure virus-induced apoptosis, free nucleosomal DNA in cytoplasm was detected using the Cell Death Detection ELISA kit (Roche, Mannheim, Germany) according to the manual. Infected cells were pelleted by centrifugation and lysed with the lysis buffer from the kit. $20 \mu \mathrm{l}$ of the cytoplasmic fraction of cell lysates was used to examine the release of free nucleosomal DNA.

\section{Annexin- $\mathrm{V}$ and $\mathrm{PI}$ double staining}

NDV-induced CPE is associated with apoptosis. To evaluate morphological changes in infected cells, we used Annexin-V and PI that can differentiate changes in cellular structure in the process of programmed cell death. In the early stage of apoptosis, phosphatidylserine (PS) exposes upon the outer leaflet of the cell membrane, which can be detected by Annexin- $\mathrm{V}$ with high affinity. In the late stage of apoptosis, leaky necrotic cells release DNA that can be stained by PI. AnnexinV-FLUOS staining kit (Roche, Mannheim, Germany) was used to label splenocytes collected at $24 \mathrm{~h}$ pi as recommended by the producer.

Table 2 Primers for real-time PCR

\begin{tabular}{|c|c|c|c|}
\hline Target RNA & Primer sequence $\left(5^{\prime}-3^{\prime}\right)$ & Accession no. & Product size (bp) \\
\hline $\mathrm{IFN-a}$ & Forward primer: CCACGACATCCTTCAGCACCT Reverse primer: TGAGGAGGCTTTGGCGTTG & NM_205427.1 & 89 \\
\hline IFN- $\beta$ & Forward primer: TGCACAGCATCCTACTGCTCTTG Reverse primer: GTTGGCATCCTGGTGACGAA & NM_001024836.1 & 83 \\
\hline IFN- $\gamma$ & $\begin{array}{l}\text { Forward primer: AGCATTTGAACTGAGCCATCACC Reverse primer: } \\
\text { CGTCAGCTACATCTGAATGACTTG }\end{array}$ & NM_205149.1 & 181 \\
\hline$\beta$-actin & Forward primer: ATTGTCCACCGCAAATGCTTC Reverse primer: AAATAAAGCCATGCCAATCTCGTC & NM_205518.1 & 113 \\
\hline M & Forward primer: GCTTGTGAAGGCGAGAGGTG Reverse primer: AACCTGGGGAGAGGCATTG & $-{ }^{a}$ & 99 \\
\hline
\end{tabular}

${ }^{a}$ : primers for viral $\mathrm{M}$ gene were designed based on the results of sequence comparison as described in the Methods. 


\section{Statistical analysis}

Statistical significance of differences between experimental groups was determined using the IndependentSamples $\mathrm{T}$ test. Values of $P<0.05$ were considered significant.

\section{Abbreviations \\ CEF: Chicken embryo fibroblasts; CPE: Cytopathic effect; ELISA: Enzyme linked immunosorbent assay; IFN: Interferon; IRFs: IFN regulatory factors; M: Matrix; MOI: Multiplicity of infection; NDV: Newcastle disease virus; Ng: Nanogram; PBS: Phosphate-buffered saline; Pi: Post-inoculation; PI: Proidium iodid; PKR: Protein kinase R; PS: Phosphatidylserine; qRT-PCR: Quantitative real-time polymerase chain reaction; SPF: Specific-pathogen-free; TCID 50 : 50\% tissue culture infective dose; TRAIL: TNF-related apoptosis-inducing ligand.}

\section{Competing interests}

The authors declare that they have no competing interests.

\section{Authors' contributions}

$\mathrm{ZH}$ and $\mathrm{XL}$ conceived and designed the experiments. $\mathrm{ZH}, \mathrm{JH}$ and $\mathrm{JZ}$ performed the experiments. $\mathrm{SH}, \mathrm{XWL}$ and XW contributed to the design of the study and revision of the draft. All the authors have read and approved the final manuscript.

\section{Authors' information}

${ }^{1}$ Animal Infectious Disease Laboratory, ${ }^{2}$ Ministry of Education Key Lab for Avian Preventive Medicine, School of Veterinary Medicine, Yangzhou University, 12 East Wenhui Road, Yangzhou, Jiangsu Province, 225009, China.

\section{Acknowledgements}

This work was supported by the National Natural Science Foundation of China (key program, grant number: 30630048), the Earmarked Fund for Modern Agro-industry Technology Research System (grant number: nycytx-41-G07), A Project Funded by the Priority Academic Program Development of Jiangsu Higher Education Institutions (PAPD) and Program for Changjiang Scholars and Innovative Research Team in University (PCSIRT, IRT0978).

Received: 11 August 2011 Accepted: 20 June 2012

Published: 18 September 2012

\section{References}

1. Liu XF, Wan HQ, Ni XX, Wu YT, Liu WB: Pathotypical and genotypical characterization of strains of Newcastle disease virus isolated from outbreaks in chicken and goose flocks in some regions of China during 1985-2001. Arch Virol 2003, 148:1387-1403.

2. Mase M, Imai K, Sanada Y, Sanada N, Yuasa N, Imada T, Tsukamoto K, Yamaguchi S: Phylogenetic analysis of Newcastle disease virus genotypes isolated in Japan. J Clin Microbiol 2002, 40:3826-3830.

3. Bogoyavlenskiy A, Berezin V, Prilipov A, Usachev E, Lyapina O, Korotetskiy I, Zaitceva I, Asanova S, Kydyrmanov A, Daulbaeva K, et al: Newcastle disease outbreaks in Kazakhstan and Kyrgyzstan during 1998, 2000, 2001, 2003, 2004, and 2005 were caused by viruses of the genotypes VIIb and VIId. Virus Genes 2009, 39:94-101.

4. Ecco R, Brown C, Susta L, Cagle C, Cornax I, Pantin-Jackwood M, Miller PJ, Afonso CL: In vivo transcriptional cytokine responses and association with clinical and pathological outcomes in chickens infected with different Newcastle disease virus isolates using formalin-fixed paraffin-embedded samples. Vet Immunol Immunopathol 2011, 141:221-229.

5. Susta L, Miller PJ, Afonso CL, Brown CC: Clinicopathological characterization in poultry of three strains of Newcastle disease virus isolated from recent outbreaks. Vet Pathol 2011, 48:349-360.

6. Wan $H$, Chen L, Wu L, Liu X: Newcastle disease in geese: natural occurrence and experimental infection. Avian Pathol 2004, 33:216-221.

7. Peeters BP, de Leeuw OS, Koch G, Gielkens AL: Rescue of Newcastle disease virus from cloned CDNA: evidence that cleavability of the fusion protein is a major determinant for virulence. J Virol 1999, 73:5001-5009.

8. de Leeuw OS, Koch G, Hartog L, Ravenshorst N, Peeters BP: Virulence of Newcastle disease virus is determined by the cleavage site of the fusion protein and by both the stem region and globular head of the haemagglutinin-neuraminidase protein. J Gen Virol 2005, 86:1759-1769.

9. Dortmans JC, Rottier PJ, Koch G, Peeters BP: The viral replication complex is associated with the virulence of Newcastle disease virus. J Virol 2010, 84:10113-10120

10. Rue CA, Susta L, Cornax I, Brown CC, Kapczynski DR, Suarez DL, King D , Miller PJ, Afonso CL: Virulent Newcastle disease virus elicits a strong innate immune response in chickens. J Gen Virol 2011, 92:931-939.

11. Cheung CY, Poon LL, Lau AS, Luk W, Lau YL, Shortridge KF, Gordon S, Guan $Y$, Peiris JS: Induction of proinflammatory cytokines in human macrophages by influenza A (H5N1) viruses: a mechanism for the unusual severity of human disease? Lancet 2002, 360:1831-1837.

12. Suzuki K, Okada H, Itoh T, Tada T, Mase M, Nakamura K, Kubo M, Tsukamoto K: Association of increased pathogenicity of Asian H5N1 highly pathogenic avian influenza viruses in chickens with highly efficient viral replication accompanied by early destruction of innate immune responses. J Virol 2009, 83:7475-7486.

13. Kommers GD, King DJ, Seal BS, Carmichael KP, Brown CC: Pathogenesis of six pigeon-origin isolates of Newcastle disease virus for domestic chickens. Vet Pathol 2002, 39:353-362.

14. Kommers GD, King DJ, Seal BS, Brown CC: Pathogenesis of chickenpassaged Newcastle disease viruses isolated from chickens and wild and exotic birds. Avian Dis 2003, 47:319-329.

15. Harrison L, Brown C, Afonso C: Zhang J. Susta L: Early Occurrence of Apoptosis in Lymphoid Tissues from Chickens Infected with Strains of Newcastle Disease Virus of Varying Virulence. J Comp Pathol; 2011.

16. Tisoncik JR, Korth MJ, Simmons CP, Farrar J, Martin TR, Katze MG: Into the Eye of the Cytokine Storm. Microbiol Mol Biol Rev 2012, 76:16-32.

17. Huang Z, Krishnamurthy S, Panda A, Samal SK: Newcastle disease virus V protein is associated with viral pathogenesis and functions as an alpha interferon antagonist. J Virol 2003, 77:8676-8685.

18. Barber GN: Host defense, viruses and apoptosis. Cell Death Differ 2001, 8:113-126.

19. Daidoji T, Koma T, Du A, Yang CS, Ueda M, Ikuta K, Nakaya T: H5N1 avian influenza virus induces apoptotic cell death in mammalian airway epithelial cells. J Virol 2008, 82:11294-11307.

20. Uiprasertkul M, Kitphati R, Puthavathana P, Kriwong R, Kongchanagul A, Ungchusak K, Angkasekwinai S, Chokephaibulkit K, Srisook K, Vanprapar N, Auewarakul P: Apoptosis and pathogenesis of avian influenza A (H5N1) virus in humans. Emerg Infect Dis 2007, 13:708-712.

21. Mok CK, Lee DC, Cheung CY, Peiris M, Lau AS: Differential onset of apoptosis in influenza A virus H5N1- and H1N1-infected human blood macrophages. J Gen Virol 2007, 88:1275-1280.

22. Edinger AL, Thompson CB: Death by design: apoptosis, necrosis and autophagy. Curr Opin Cell Biol 2004, 16:663-669.

23. Lam KM: Growth of Newcastle disease virus in chicken macrophages. J Comp Pathol 1996, 115:253-263.

24. Lam KM: Newcastle disease virus-induced apoptosis in the peripheral blood mononuclear cells of chickens. J Comp Pathol 1996, 114:63-71.

\section{doi:10.1186/1743-422X-9-208}

Cite this article as: Hu et al:: Strong innate immune response and cell death in chicken splenocytes infected with genotype VIld Newcastle disease virus. Virology Journal 2012 9:208.

\section{Submit your next manuscript to BioMed Central and take full advantage of:}

- Convenient online submission

- Thorough peer review

- No space constraints or color figure charges

- Immediate publication on acceptance

- Inclusion in PubMed, CAS, Scopus and Google Scholar

- Research which is freely available for redistribution 